Journal of Engineering and Applied Sciences 14 (11): 3557-3570, 2019

ISSN: 1816-949X

(C) Medwell Journals, 2019

\title{
Statistical Analysis for Studying Autoclave Test
}

\author{
Marwa Asad Salih and Naghm M. Saidik \\ Faculty of Engineering, University of Kufa, Al-Najaf, Al-Ashraf, Iraq
}

\begin{abstract}
Late expansion may occur as a result of the hydration of calcium oxide and magnesium oxide in the hardened concrete which if exceeded, may cause a cracks. One of the modern methods used to estimate the stability of the cement size (expansion) is the autoclave method, this study aim to estimate the stability of the cement and this will gives an indication of the late expansion. The statistical program "Statistica" were used in the analysis of the factors affecting the results of autoclave test these factors were $\left(\mathrm{CaO}, \mathrm{SO}_{3}, \mathrm{MgO}, \mathrm{Al}_{2} \mathrm{O}_{3}\right.$, $\mathrm{Fe}_{2} \mathrm{O}_{3}$, free lime, LOI, IR, LSF). The linear regression method was used and the study were done in two ways individually and again in groups. The multiple linear regression was found to be very appropriate for predicting the autoclave expansion of Portland cement. On the other hand there is no significant variance in the value of correlation coefficient when studying the factors individually or in groups, so, it is preferable to use models with individual factors for facilitate of research.
\end{abstract}

$\underline{\text { Key words: Statistical analysis, autoclave expansion, } \mathrm{MgO}, \mathrm{CaO} \text {, soundness of cement, correlation coefficient }}$

\section{INTRODUCTION}

The presence of uncombined lime and magnesium oxide in the form of periclase in Portland cement production could cause unsoundness and that by a delayed very high expansion in cement-based constructions this could be explained by the formation of $\mathrm{Ca}(\mathrm{OH})_{2}$ and $\mathrm{Mg}(\mathrm{OH})_{2}$ due to the existence of (free $\mathrm{CaO}$ ) and $\mathrm{MgO}$ in the mixture it is not clear yet how much is the amount of free $\mathrm{CaO}$ and $\mathrm{MgO}$ that could cause a damage in the cement-based constructions.

Gonnerman et al. (1953) they were working to determine the percentage of free $\mathrm{CaO}$ and $\mathrm{MgO}$ that could cause an excessive expansion and they found it about (1.4-2\%) and (4-5\%), respectively. Rehsi and Majumdar (1967) showed that beyond 5\% of $\mathrm{MgO}$, the volume expansion of cement rises aggressively.

According to Lea (1970) cement with total $\mathrm{MgO}$ content in the range of $(1-2 \%)$ and free lime below (2\%) will pass the autoclave test. However, cement with high percentage of $\mathrm{MgO}$, the free $\mathrm{CaO}$ need to be below $1 \%$ to ensure its compliance.

Czermin (1980) found that cement containing $\mathrm{MgO}$ below $(3.5 \%)$ could fail in soundness autoclave test. the differentiation in results are related to several factors such as cement fineness, cooling conditions, $\mathrm{C}_{3} \mathrm{~A}$ content, alkalis, etc.

Huntzinger and Eatmon (2009) during cement hydration $\mathrm{CaO}$ in conjunction with $\mathrm{SiO}_{2}, \mathrm{Al}_{2} \mathrm{O}_{3}$ and $\mathrm{Fe}_{2} \mathrm{O}_{3}$ and this what gives the Portland cement its hardness due to the formation of calcium aluminosilicates and aluminoferrite hydrate. Increasing the percentage of $\mathrm{MgO}$ $(>2 \%)$ in the Portland cement may affect negatively the cement's soundness, especially, at late ages, a high percentage of $\mathrm{SO}_{3}$ tends to cause unsoundness of cement. Americans in their standard, ASTM C618 limits $\mathrm{SO}_{3}$ to 4 and $5 \%$ whilst the Indian standard limits $\mathrm{SO}_{3}$ to $2.75 \%$.

According to Anonymous (2005) the main factor controlling cement expansion is the $\mathrm{CaO}, \mathrm{MgO}$ content due to the formation of $\mathrm{Ca}(\mathrm{OH})_{2}, \mathrm{Mg}(\mathrm{OH})_{2}$ (in the last ions resulting from $\mathrm{CaO}, \mathrm{MgO}$, respectively). Chatterji (1995) showed that the mechanism of expansion of both oxides is similar but $\mathrm{CaO}$ is higher because it is more soluble than $\mathrm{MgO}$.

Lea (2004) stated that the overlap between these two oxidants is what cause this expansion. It was found that the cement containing $\mathrm{CaO}$ by $<2 \%$ will succeed in testing the water-solvent (autoclave) when the total $\mathrm{MgO}$ content is low (1-2\%). However, in the high level of $\mathrm{MgO}$, free $\mathrm{CaO}$ content is necessary to have a $\mathrm{CaO}$ concentration of $<1 \%$ in order to be safe.

Neville (1995) noted that (the determinant in the selection of a autoclave) is affected by $\mathrm{MgO}, \mathrm{CaO}$ and not affected by $\mathrm{CaSO}_{4}$ in contrast to significant research by researchers who indicated that $\mathrm{CaSO}_{4}$ affects the results of a autoclave. Latif (2001) suggested using the autoclave test to determine the optimum ratio of gypsum content added during clinker milling in the cement industry.

In addition to the chemical composition of the cement is a key factor affecting the expansion and the results of the analysis of the autoclave test. Lea (2004) explained

Corresponding Author: Marwa Asad Salih, Faculty of Engineering, University of Kufa, Al-Najaf, Al-Ashraf, Iraq 
that the degree of stability of the cement depends on the size of the crystals as the small crystals dissolve more quickly and without the production of compressed internal pressure.

Chopra showed that the process of grinding the clinker containing a high percentage of $\mathrm{MgO}$ to a high degree of smoothness can be considers as an effective way for the production of fixed-size cement. Czernin (1980) found that by increasing the fineness of free $\mathrm{CaO}$, the expansion decreases and became more regular. Essa statistically proved that LSF and LOI are of the factors that reduce the expansion of cement.

Borhan and Al-Rawi (2016) showed that there is a considerable effect of $\mathrm{MgO}$ content on autoclave expansion tests and on the optimum gypsum content in cement. The increase in $\mathrm{MgO}$ content results in an increase in the autoclave expansion and a reduction in the optimum gypsum content. The autoclave test is not sensitive to the variation in $\mathrm{SO}_{3}$ content in cement at low $\mathrm{MgO}$ value. The sensitivity is increased with increase $\mathrm{MgO}$ content.

Al-Attar (2013) the model was tested with new raw data and the predictions were highly correlated to the experimental results $(r=0.92)$, a t-test was carried out and it showed that there is no difference between means of experimental and predicted sets of values. The good predictions give the chance to make use of the model in saving time and money.

Data collection: Data were collected from various construction laboratories and it consists of (40) different cement samples taken from different Iraqi and foreign cement factories (29) of the samples were ordinary Portland cement while the other (11) samples were sulphate resisting Portland cement.

Statistical analysis: The statistical analysis implemented by using the statistical program (statistica) and the factors (as individuals) that studied in the present study were ( $\mathrm{MgO}, \mathrm{CaO}, \mathrm{SiO}_{2}, \mathrm{Fe}_{2} \mathrm{O}_{3}, \mathrm{Al}_{2} \mathrm{O}_{3}, \mathrm{SO}_{3}$, L.O.I, IR, L.S.F, IST, FST, free lime) and groups factors were $(\mathrm{MgO} \mathrm{CaO}, \mathrm{MgO}$ $\mathrm{CaO}$ Blane, $\mathrm{MgO} \mathrm{CaO} \mathrm{SO}, \mathrm{MgOCaO} \mathrm{SO}$ Blane). The statistical factors that used to evaluate the models in this research are as below with definition of each.

Multiple R: The coefficient of multiple correlation is the positive square root of $\mathrm{R}^{2}$ (the coefficient of multiple determination). This statistical factor is useful in multivariate regression (i.e., multiple independent variables) when it is wanted to describe the relationship between the variables.
$\mathbf{R}^{2}$ : This coefficient of multiple determination measures the reduction, in the total variation of the dependent variable due to the (multiple) independent variables:

$$
\mathrm{R}^{2}=1-[\text { Residual SS/Total SS }]
$$

Where:

Residual SS $=$ The Error Sums of Square

Total SS $=$ The total Sums of Square

The $\mathrm{R}^{2}$ value is an indicator of how well the model fits the data, $\mathrm{R}^{2}$ close to 1.0 indicates that it has accounted for almost all of the variability with the variables specified in the model.

Adjusted $\mathbf{R}^{2}$ : The $\mathrm{R}^{2}$ is adjusted by dividing the error sum of squares and total sums of square by their respective degrees of freedom:

$$
\text { Adjusted } \mathrm{R}^{2}=1-[(\text { Residual SS/dfr)/(Total SS/dft)] }
$$

SE of estimate: This statistic coefficient measures the dispersion of the observed values about the regression line."

F-value: The F-value is used as a test of the relationship between the dependent variable and the set of independent variables:

$$
\mathrm{F}=\text { Regression mean square/Residual mean square }
$$

The range of difference ( $\mathrm{df}$ ) between the actual and predicted Autoclave expansion values was calculated for each model within confidence interval of 0.95 . This means that there is a probability of $95 \%$ of difference between the actual and the predicted values falls within a range of $\pm \mathrm{df}$, thus, the actual values equals to predicted values \pm df."

\section{MATERIALS AND METHODS}

Independent variables: The following variables are selected to be as the independent variables:

The four main compounds of Portland cement (i.e., $\mathrm{C}_{3} \mathrm{~S}, \mathrm{C}_{2} \mathrm{~S}, \mathrm{C}_{3} \mathrm{~A}$ and $\mathrm{C}_{4} \mathrm{AF}$ ) which were calculated using Bogue's equations

. The fineness of cement (in terms of Blaine specific surface)

Chemical analysis parameters (i.e. $\mathrm{MgO}$, Free $\mathrm{CaO}$, $\mathrm{SO}_{3}, \mathrm{LOI}, \mathrm{IR}$ and LSF) 


\section{RESULTS AND DISCUSSION}

Study of the factors affecting the results of the autoclave:

\section{Individual factors affecting the results of the autoclave test}

$\mathbf{C a O} \%$ : $\mathrm{CaO} \%$ selected to be as the independent variable, the final form of this model is as shown in Table 1. The relationship between the residuals and the estimated readings of the autoclave based on $\mathrm{CaO}$ and the relationship between the actual readings and the estimated readings of the autoclave based on $\mathrm{CaO}$ are presented in Fig. 1 and 2. The distribution of residuals is shown in Fig. 3.

MgO\%: $\mathrm{MgO} \%$ was used as the independent variable in developing this model. The final form of this model is as illustrated in Table 2. The relationship between the residuals and the estimated readings of the autoclave based on $\mathrm{MgO}$ and The relationship between the actual readings and the estimated readings of the autoclave based on $\mathrm{MgO}$ are presented in Fig. 4 and 5. The distribution of residuals is shown in Fig. 6.

$\mathrm{SiO}_{2} \%$ : $\mathrm{SiO}_{2} \%$ was used as the independent variable in developing this model. The final form of this model is as illustrated in Table 3 . The relationship between the residuals and the estimated readings of the autoclave based on $\mathrm{SiO}_{2}$ and the relationship between the actual readings and the estimated readings of the autoclave based on $\mathrm{SiO}_{2}$ are presented in Fig. 7 and 8. The distribution of residuals is shown in Fig. 9.

$\mathbf{A l}_{2} \mathbf{O}_{3} \%: \mathrm{Al}_{2} \mathrm{O}_{3} \%$ was used as the independent variable in developing this model. The final form of this model is as illustrated in Table 4. The relationship between the residuals and the estimated readings of the autoclave based on $\mathrm{Al}_{2} \mathrm{O}_{3}$ and the relationship between the actual readings and the estimated readings of the autoclave based on $\mathrm{Al}_{2} \mathrm{O}_{3}$ are presented in Fig. 10 and 11. The distribution of residuals is shown in Fig. 12.

$\mathbf{F e}_{2} \mathbf{O}_{\mathbf{3}} \%: \mathrm{Fe}_{2} \mathrm{O}_{3} \%$ was used as the independent variable in developing this model. The final form of this model is as illustrated in Table 5. The relationship between the residuals and the estimated readings of the autoclave based on $\mathrm{Fe}_{2} \mathrm{O}_{3}$ and the relationship between the actual readings and the estimated readings of the autoclave based on $\mathrm{Fe}_{2} \mathrm{O}_{3}$ are presented in Fig. 13 and 14. The distribution of residuals is shown in Fig. 15.

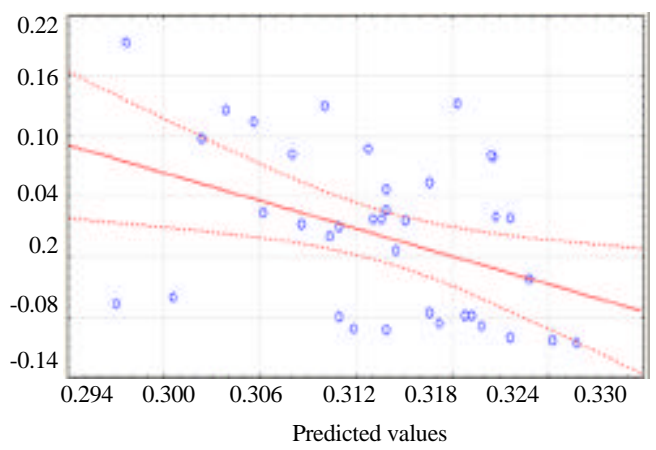

Fig. 1: The relationship between the residuals and the estimated readings of the autoclave based on $\mathrm{CaO}$; Predicted vs. Residual scores dependent variables: AUTO_EXP

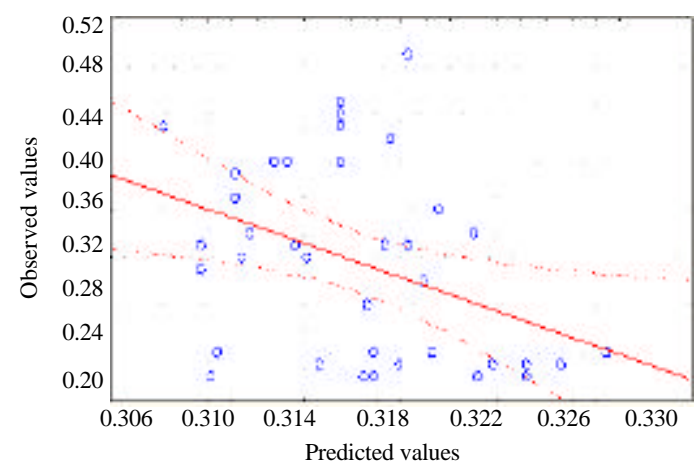

Fig. 2: The relationship between the actual readings and the estimated readings of the autoclave based on $\mathrm{CaO}$; Predicted vs. observed values dependent variables: AUTO_EXP

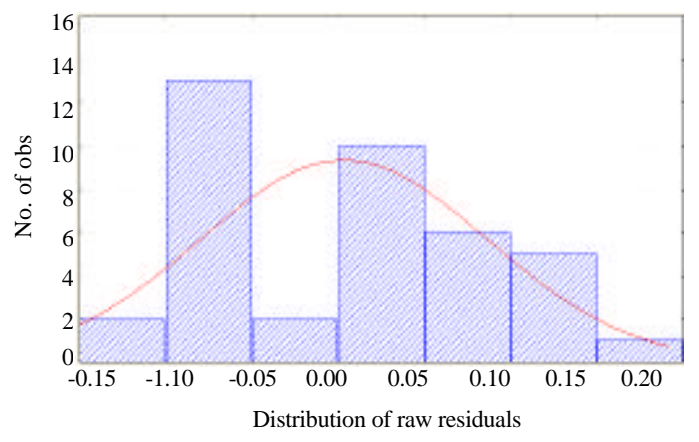

Fig. 3: Histogram and normal distribution of residual values depending on $\mathrm{CaO}$

$\mathbf{S O}_{3} \%: \mathrm{SO}_{3} \%$ was used as the independent variable in developing this model. The final form of this model is as illustrated in Table 6 . The relationship between the residuals and the estimated readings of the autoclave based on $\mathrm{SO}_{3}$ and the relationship between the actual readings and the estimated 
Table 1: Linear regression results of the autoclave based on $\mathrm{CaO} \%$

\begin{tabular}{lcccccc}
\hline Dependent variabkles & Independent var. (\%) & Multiple R & $\mathrm{R}^{2}$ & Adjusted F & SE & Beta \\
\hline Auto exp. & $\mathrm{CaO}$ & 0.96839035 & 0.93777987 & 572.7348 & 0.081910287 & 0.968 \\
\hline
\end{tabular}

Table 2: Results of linear regression of the autoclave depending on $\mathrm{MgO}$

\begin{tabular}{lcccccc}
\hline Dependent variabkles & Independent variabkles & Multiple $\mathrm{R}$ & $\mathrm{R}^{2}$ & Adjusted F & SE & Beta \\
\hline Auto exp. & $\mathrm{MgO}$ & 0.9644914 & 0.93983164 & 593.5612 & 0.080548430 & 0.969
\end{tabular}

Table 3: Results of the linear regression of the autoclave based on $\mathrm{SiO}_{2}$

\begin{tabular}{lllllll} 
Dependent variabkles & Independent & Multiple R & $\mathrm{R}^{2}$ & Adjusted F & SE & Beta \\
\hline
\end{tabular}

\begin{tabular}{lllllll}
\hline Auto exf. & $\mathrm{SiO}_{2}$ & 0.96779167 & 0.93495284 & 561.565 & 0.082669752 & 0.96 \\
\hline
\end{tabular}

Table 4: Results of linear regression of the autoclave depending on $\mathrm{Al}_{2} \mathrm{O}_{3}$

\begin{tabular}{lllllll}
\hline Dependent variabkles & Independent & Multiple $\mathrm{R}$ & $\mathrm{R}^{2}$ & Adjusted & $\mathrm{S}$ & Beta \\
\hline
\end{tabular}

\begin{tabular}{lllllll}
\hline Auto exp. & $\mathrm{AI}_{2} \mathrm{O}_{3}$ & 0.9712094 & 0.94320569 & 631.6116 & 0.078226391 & 0.971 \\
\hline
\end{tabular}

Table 5: Linear regression results of the autoclave based on $\mathrm{Fe}_{2} \mathrm{O}_{3}$

\begin{tabular}{lcccccc}
\hline Dependent variabkles & Independet variabkles & Multiple R & $\mathrm{R}^{2}$ & Adjusted F & SE & Beta \\
\hline Auto exp. & $\mathrm{Fe}_{2} \mathrm{O}_{3}$ & 0.92007968 & 0.84654662 & 209.6322 & 0.128635609 & 0.92 \\
\hline
\end{tabular}

Table 6: Results of linear regression of the scale based on $\mathrm{SO}_{3}$

\begin{tabular}{lcccrcc}
\hline Dependent variabkles & Independent var. & Multiple $\mathrm{R}$ & $\mathrm{R}^{2}$ & Adjusted F & SE & Beta \\
\hline Auto exp. & $\mathrm{SO}_{3}$ & 0.97630404 & 0.95316957 & 773.4382 & 0.071061937 & 0.976 \\
\hline
\end{tabular}

Table 7: Results of linear regression of the autoclave based on free lime

\begin{tabular}{lcccrrr}
\hline Dependent variabkles & Independent variabkles & Mulitple R & $\mathrm{R}^{2}$ & Adjusted F & SE & Beta \\
\hline Auto exp. & Free lime & 0.96485076 & 0.93093707 & 512.2222 & 0.086297003 & 0.965 \\
\hline
\end{tabular}

Table 8: Results of linear regression of the autoclave depending on LOI

\begin{tabular}{lcccccc}
\hline Dependent variabkles & Independent variabkles & Multiple R & $\mathrm{R}^{2}$ & Adjusted F & SE & Beta \\
\hline Auto exp. & L-O-I & 0.91665561 & 0.84025751 & 199.8229 & 0.13245134 & 0.917 \\
\hline
\end{tabular}

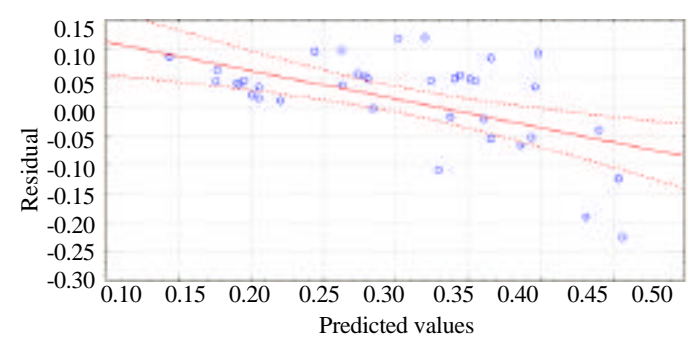

Fig. 4: The relationship between the residual and the estimated readings of the autoclave based on $\mathrm{MgO}$; Predicted vs. residual scores dependent variables: AUTO_EXP

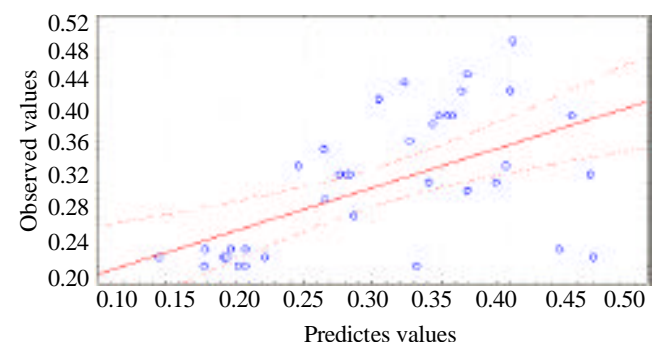

Fig. 5: The relationship between the actual readings and the estimated readings of the autoclave based on $\mathrm{MgO}$; Predicted vs. observed values dependent variables: AUTO_EXP

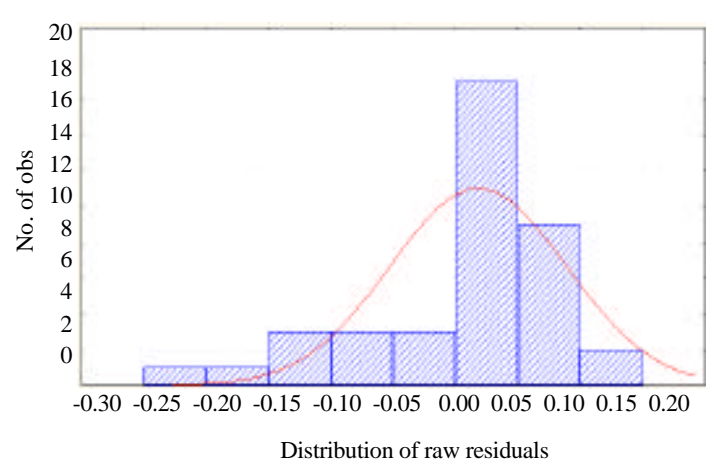

Fig. 6: Histogram and normal distribution of residual values depending on $\mathrm{MgO}$

readings of the autoclave based on $\mathrm{SO}_{3}$ are presented in Fig. 16 and 17. The distribution of residuals is shown in Fig. 18.

Free lime\%: Free lime\% was used as the independent variable in developing this model. The final form of this model is as illustrated in Table 7. The relationship between the residuals and the estimated readings of the autoclave based on Free Lime and the relationship 


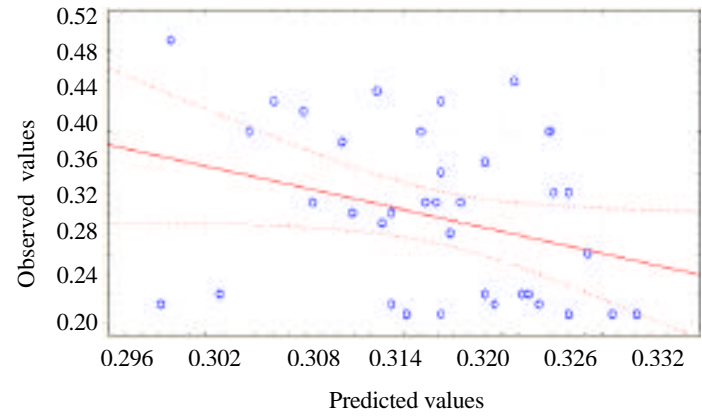

Fig. 7: The relationship between the residual and the estimated readings of the autoclave based on $\mathrm{SiO}_{2}$; Predicted vs. observed values dependent variables: AUTO_EXP

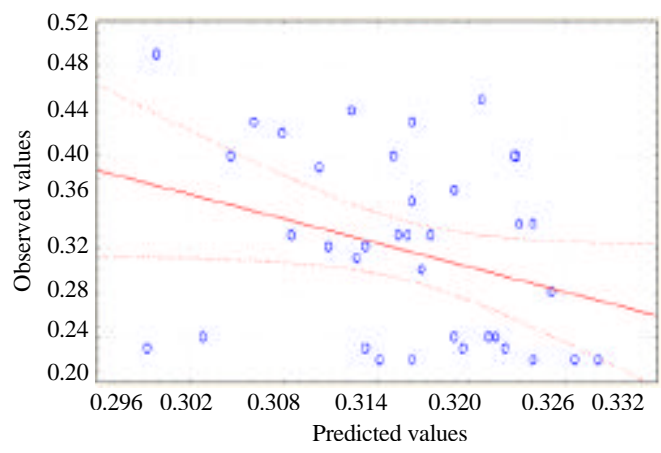

Fig. 8: The relationship between the actual readings and the estimated readings of the autoclave based on $\mathrm{SiO}_{2}$; Predicted vs. observed values dependent variables: AUTO_EXP

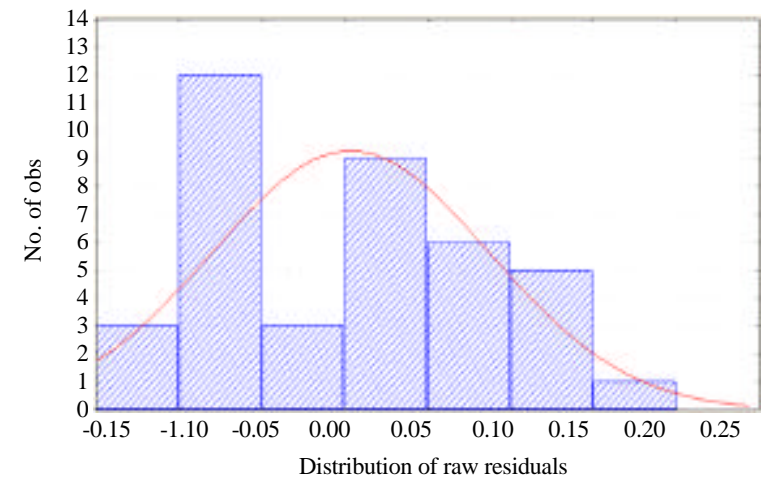

Fig. 9: Histogram and normal distribution of residual values based on $\mathrm{SiO}_{2}$

between the actual readings and the estimated readings of the autoclave based on free lime are presented in Fig. 19 and 20. The distribution of residuals is shown in Fig. 21.

LOI\%: L.O.I\% was used as the independent variable in developing this model. The final form of this model

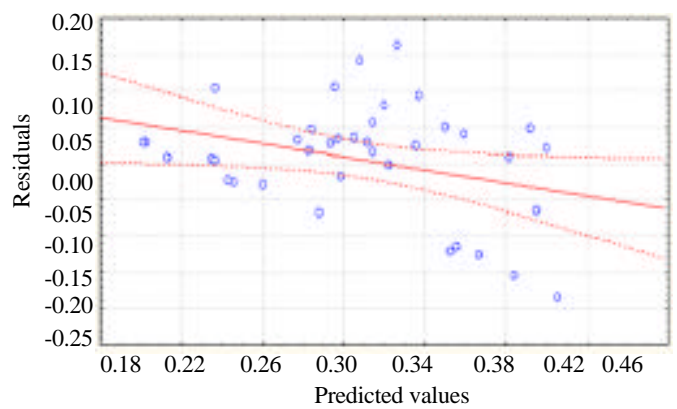

Fig. 10: The relationship between the residual and the estimated readings of the autoclave based on $\mathrm{Al}_{2} \mathrm{O}_{3}$; Predicted vs. observed values dependent variables: AUTO_EXP

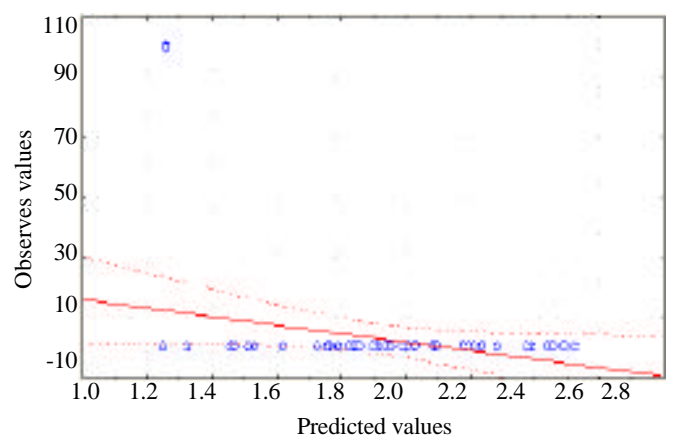

Fig. 11: The relationship between the residual and the estimated readings of the autoclave based on $\mathrm{Al}_{2} \mathrm{O}_{3}$; Predicted vs. observed values dependent variables: AUTO_EXP

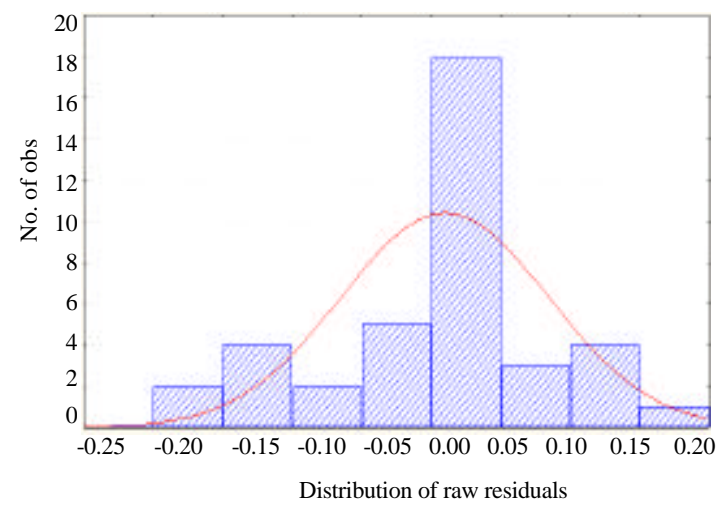

Fig. 12: Histogram and normal distribution of residual values depending on $\mathrm{Al}_{2} \mathrm{O}_{3}$

is as illustrated in Table 8 . The relationship between the residuals and the estimated readings of the autoclave based on LOI and the relationship between the actual readings and the estimated readings of the autoclave based on LOI are presented in Fig. 22 and 23. The distribution of residuals is shown in Fig. 24. 


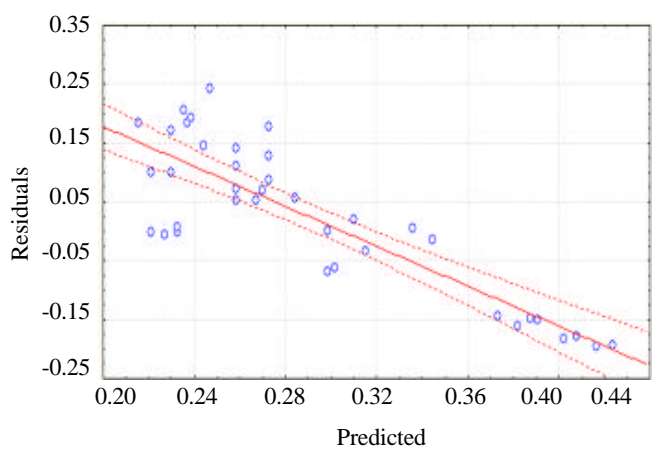

Fig. 13: The relationship between the residual and the estimated readings of the autoclave based on $\mathrm{Fe}_{2} \mathrm{O}_{3}$; Predicted vs. residual scores dependent variables: AUTO_EXP

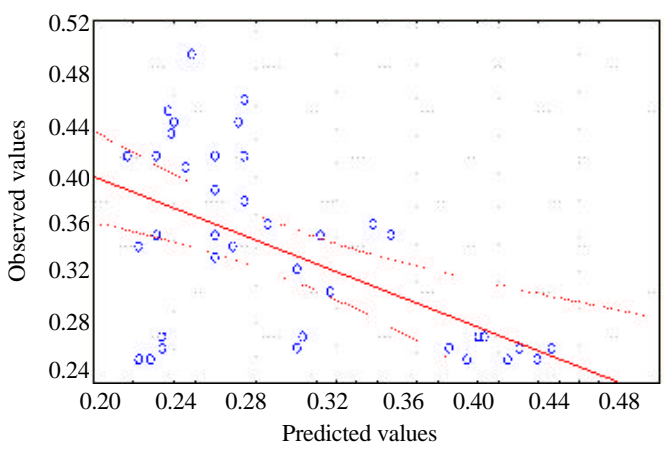

Fig. 14: The relationship between the actual readings and the estimated readings of the autoclave based on $\mathrm{Fe}_{2} \mathrm{O}_{3}$; Predicted vs. observed values dependent variables: AUTO EXP

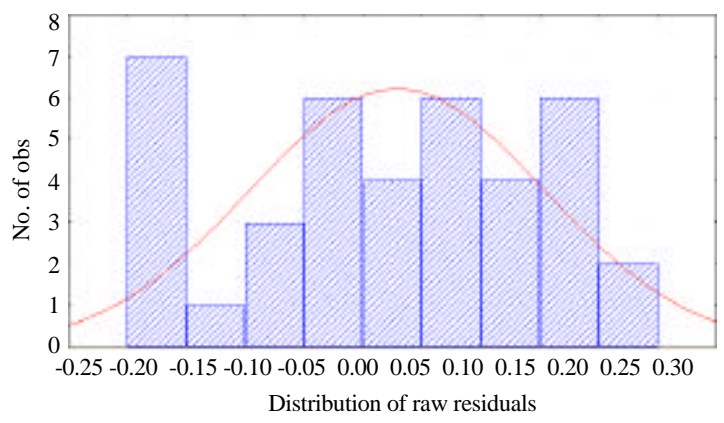

Fig. 15: Histogram and normal distribution of residual values depending on $\mathrm{Fe}_{2} \mathrm{O}_{3}$

IR\%: IR\% was used as the independent variable in developing this model. The final form of this model is as illustrated in Table 9. The relationship between the residuals and the estimated readings of the autoclave based on IR and the relationship between the actual readings and the estimated readings of the autoclave based on IR are presented in Fig. 25 and 26. The distribution of residuals is shown in Fig. 27.

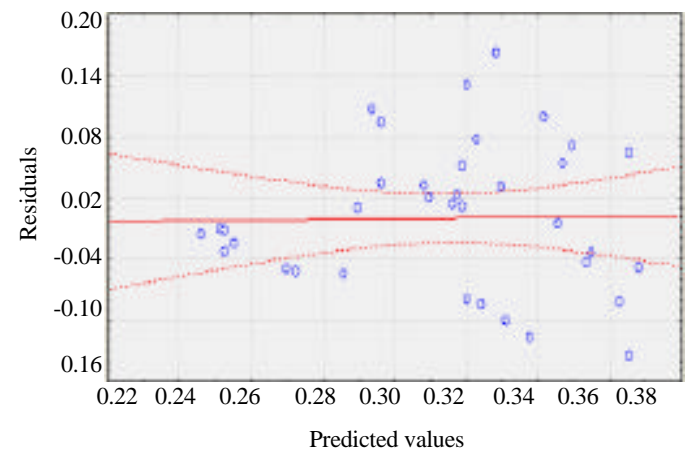

Fig. 16: The relationship between the residual and the estimator's estimated readings of the autoclave based on $\mathrm{SO}_{3}$; Predicted vs. residual scores dependent variables: AUTO_EXP

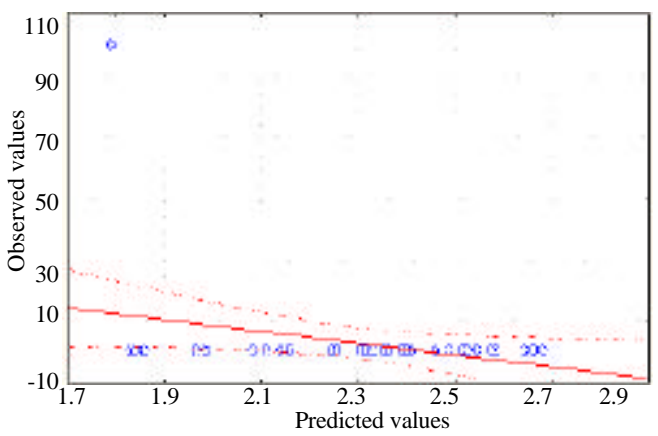

Fig. 17: The relationship between the actual and the estimator's estimated readings of the autoclave based on $\mathrm{SO}_{3}$; Predicted vs. observed values dependent variables: AUTO_EXP

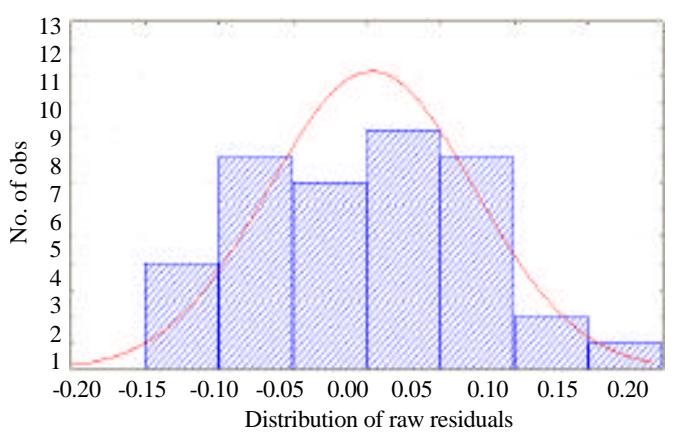

Fig. 18: Histogram and normal distribution of residual values depending on $\mathrm{SO}_{3}$

LSF\%: LSF\% was used as the independent variable in developing this model. The final form of this model is as illustrated in Table 10. The relationship between the residuals and the estimated readings of the autoclave based on LSF and the relationship between the actual readings and the estimated readings of the autoclave 


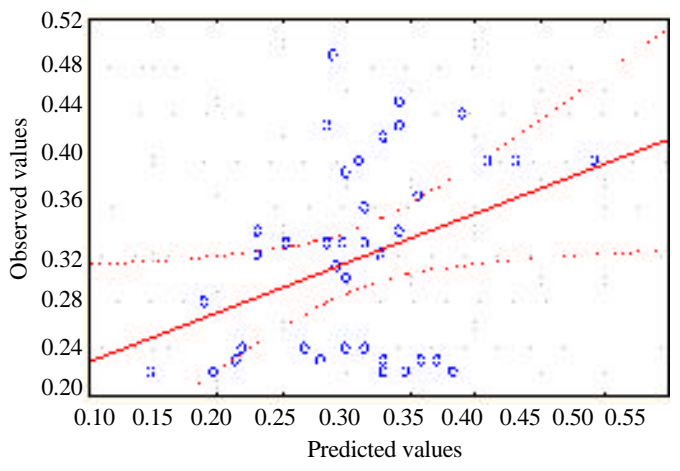

Fig. 19: The relationship between the residual and the estimated readings of the autoclave based on free lime; Predicted vs. observed values dependent variables: AUTO EXP

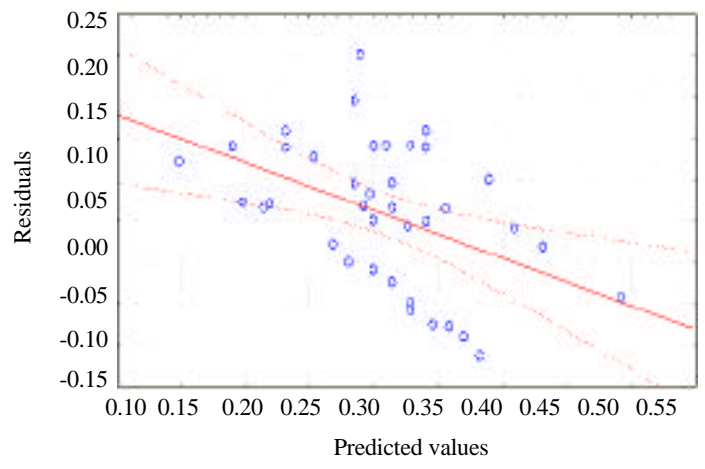

Fig. 20: The relationship between the actual readings and the estimated readings of the autoclave based on free lime; Predicted vs. observed values dependent variables: AUTO_EXP

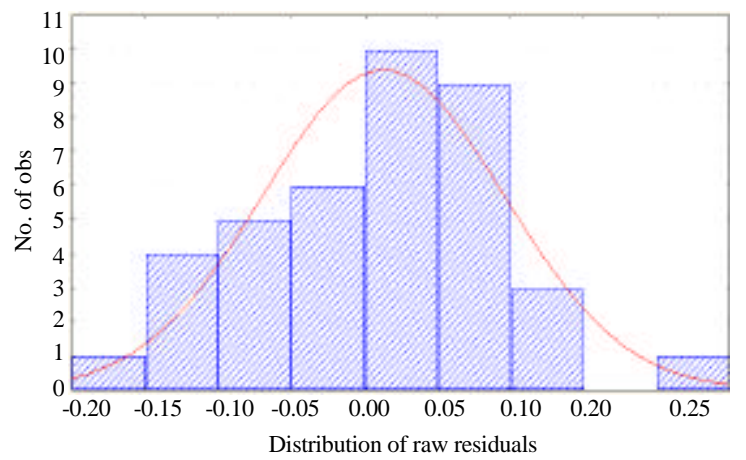

Fig. 21: Histogram and normal distribution of residual values based on free lime

based on L.S.F are presented in Fig. 28 and 29. The distribution of residuals is shown in Fig. 30: Table 9 and 10.

IST-MIN\%: IST-MIN \% was used as the independent variable in developing this model. The final form of this

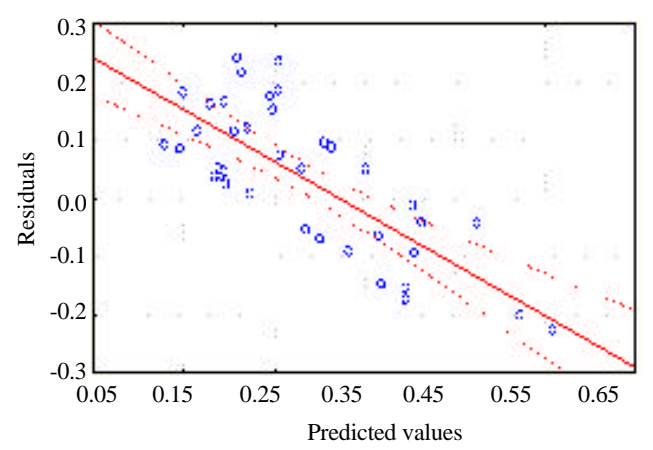

Fig. 22: The relationship between the residual and the estimated readings of the autoclave based on LOI; Predicted vs. residual scores dependent variables: AUTO_EXP

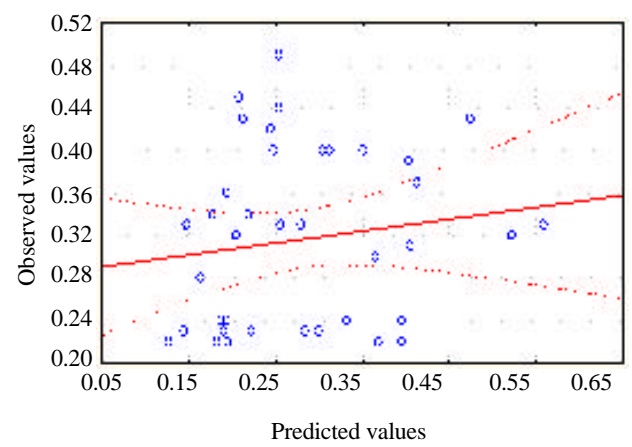

Fig. 23: The relationship between the actual and the estimated readings of the autoclave based on LOI; Predicted vs. observed values dependent variables: AUTO_EXP

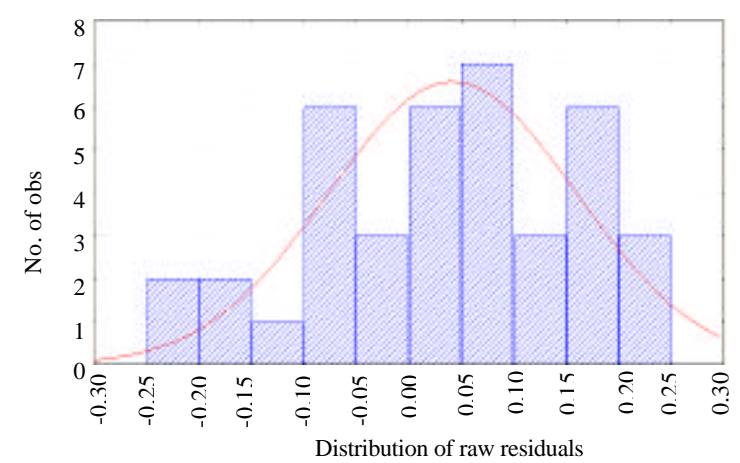

Fig. 24: The histogram and the natural distribution of residual values based on LOI

model is as illustrated in Table 11. The relationship between the residuals and the estimated readings of the autoclave based on IST-MIN and the relationship between the actual readings and the estimated readings of the autoclave based on IST-MIN are presented in Fig. 31 and 32. The distribution of residuals is shown in Fig. 33. 
Table 9: Results of the linear regression of the autocla depending on the IR

\begin{tabular}{lccccrr}
\hline Dependent variables & Independent variables & Multiple R & $\mathrm{R}^{2}$ & Adjusted F & SE & Beta \\
\hline Auto exp. & $\mathrm{IR}$ & 0.93354730 & 0.87151055 & 257.7441 & 0.117708199 & 0.934 \\
\hline
\end{tabular}

Table 10: Results of the linear regression of the autoclave based on LSF

\begin{tabular}{lcccccc}
\hline Dependent var. & Independent var. & Multiple R & $\mathrm{R}^{2}$ & Adjusted F & SE & Beta \\
\hline Auto exp. & L-S-F & 0.96857396 & 0.93813551 & 576.3458 & 0.081675855 & 0.969 \\
\hline
\end{tabular}

Table 11: Results of linear regression of the autoclave based on IST-MIN

\begin{tabular}{lcccccr}
\hline Dependent variables & Independent variables & Multiple R & $\mathrm{R}^{2}$ & Adjusted F & SE & Beta \\
\hline Auto exp. & IST-MIN & 0.95545881 & 0.91290154 & 398.2878 & 0.096912150 & 0.955 \\
\hline
\end{tabular}

Table 12: Results of the linear regression of the autoclave based on FST-MIN

\begin{tabular}{|c|c|c|c|c|c|c|}
\hline Dependent variables & Independent variables & Multiple R & $\mathrm{R}^{2}$ & Adjusted F & $\mathrm{SE}$ & Beta \\
\hline Auto exp. & FST-MIN & 0.96219655 & 0.92582220 & 374.2827 & 0.08943550 & 0.962 \\
\hline Dependent variables & ndependent variables & Multiple R & $\mathrm{R}^{2}$ & Adjusted $\mathrm{F}$ & $\mathrm{SE}$ & Beta \\
\hline Auto exp. & Blaine & 0.97406992 & 0.94881220 & 704.3644 & 0.07424421 & 0.974 \\
\hline
\end{tabular}

Table 14: Results of linear regression of the autoclave depending on $\mathrm{MgO} . \mathrm{CaO}$

\begin{tabular}{lccccccc}
\hline Dependent variables & Independent var. & Multiple $\mathrm{R}$ & $\mathrm{R}^{2}$ & Adjusted F & SE & Beta CaO & Beta \\
\hline Auto exp. & $\mathrm{MgO}+\mathrm{CaO} \%$ & 0.785141 & 0.957899 & 416.6913 & 0.069191 & 0.468 & 0.52 \\
\hline
\end{tabular}

Table 15: Results of the linear regression of the autoclave based on $\mathrm{MgO}, \mathrm{CaO}$, Blane

\begin{tabular}{llccccccc}
\hline Dependent variables & Independent var. & Multiple R & $\mathrm{R}^{2}$ & Error & Adjusted F & SE & Beta.CaO & Beta \\
\hline Auto exp. & MgOCaO.Blane & 0.97911 & 0.95866 & 278.2 & 0.06917 & 0.158 & 0.453 & 0.3 \\
\hline
\end{tabular}

Table 16: Results of linear regression of the autoclave depending on $\mathrm{MgO} \cdot \mathrm{CaO} . \mathrm{SO}_{3}$

\begin{tabular}{lcccccccc}
\hline DeP var. & Indep. & Mul.R & $\mathrm{R}^{2}$ & Adj. F & Error & Beta.MgO & Beta.CaO & Beta.SO $_{3}$ \\
\hline Auto exp. & Mgo.Cao. $\mathrm{SO}_{3}$ & 0.97967 & 0.959 & 286.5 & 0.0682 & 0.386 & 0.087 & 0.514 \\
\hline
\end{tabular}

Table 17: Results of the linear regression of the autoclave depending on $\mathrm{MgO} \cdot \mathrm{CaO} . \mathrm{SO}_{3}$. Blane

\begin{tabular}{llcccccccc}
\hline Dep var. & Indep. & $\mathrm{R}$ & $\mathrm{R}^{2}$ & Adj. F & Error & Beta. & Beta.Ca & Beta.SO & Blane \\
\hline Auto exp. & $\mathrm{MgO} . \mathrm{CaO} . \mathrm{SO}_{3}$. Blane & 0.98 & 0.9604 & 212.4 & 0.068 & 0.35 & 0.1 & 0.45 & 0.28 \\
\hline
\end{tabular}

FST-MIN\%: FST-MIN\% was used as the independent variable in developing this model. The final form of this model is as illustrated in Table 12. The relationship between the residuals and the estimated readings of the autoclave based on FST-MIN and The relationship between the actual readings and the estimated readings of the autoclave based on FST-MIN are presented in Fig. 34 and 35 .

Blaine\%: Blaine\% was used as the independent variable in developing this model. The final form of this model is as illustrated in Table 13. The relationship between the residuals and the estimated readings of the autoclave based on Blaine and the relationship between the actual readings and the estimated readings of the autoclave based on Blaine are presented in Fig. 37 and 38. The distribution of residuals is shown in Fig. 39.

\section{Study of the factors affecting the results of the autoclave in groups}

MgO, CaO: $\mathrm{MgO}, \mathrm{CaO} \%$ was used as the independent variable in developing this model. The final form of this model is as illustrated in Table 14-17. The relationship

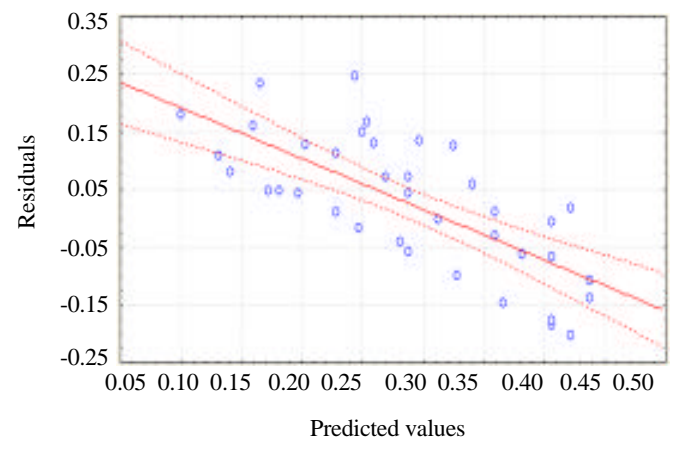

Fig. 25: The relationship between the residual and the estimated readings of the autoclave based on IR; Predicted vs. residual scores dependent variables: AUTO_EXP

between the residuals and the estimated readings of the autoclave based on $\mathrm{MgO}, \mathrm{CaO}$ and the relationship between the actual readings and the estimated readings of the autoclave based on $\mathrm{MgO}, \mathrm{CaO}$ are presented in Fig. 40 and 41. The distribution of residuals is shown in Fig. 42. it is obvious that the residuals are almost normally distributed and the residuals gathered after zero. 


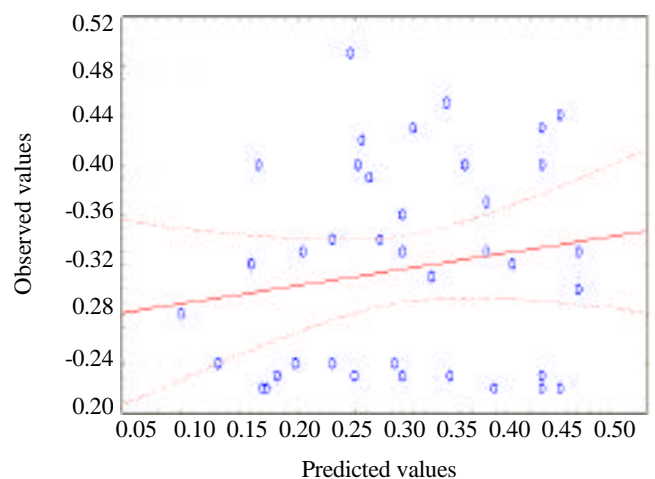

Fig. 26: The relationship between the actual readings and the estimated readings of the autoclave based on the IR; Predicted vs. observed values dependent variables: AUTO_EXP

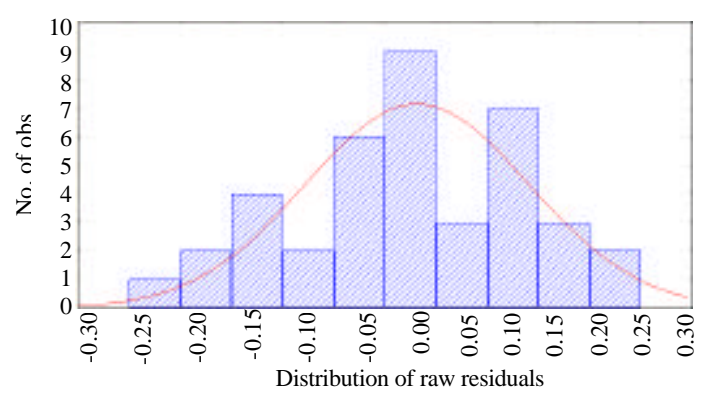

Fig. 27:Histogram and normal distribution of residual values depending on the IR

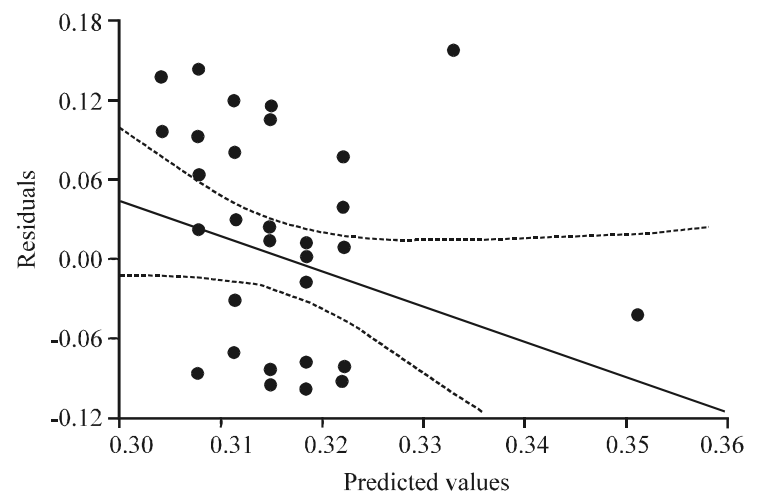

Fig. 28: The relationship between the residual and the estimated readings of the autoclave based on LSF; Predicted vs. residual scores dependent variables: AUTO_EXP

$\mathrm{MgO}, \mathrm{CaO}$, Blane: $\mathrm{MgO}, \mathrm{CaO}$, Blane\% was used as the independent variable in developing this model. The final form of this model is as illustrated in Table 15. The relationship between the residuals and the estimated

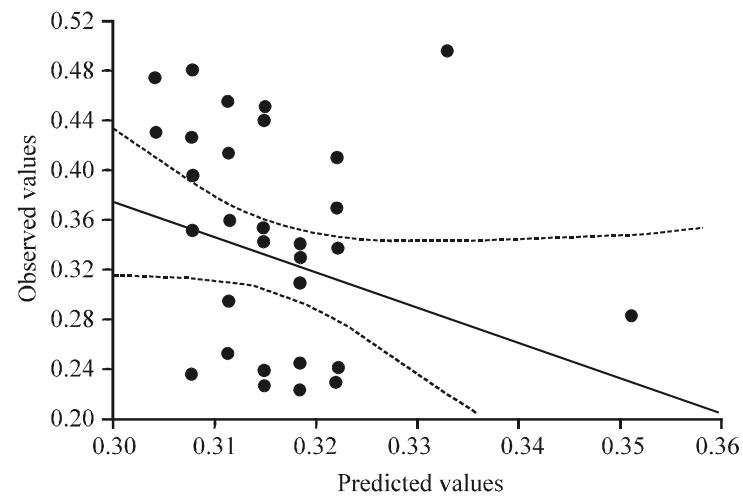

Fig. 29: The relationship between the actual readings and the estimated readings of the autoclave based on LSF; Predicted vs. observed values dependent variables: AUTO_EXP

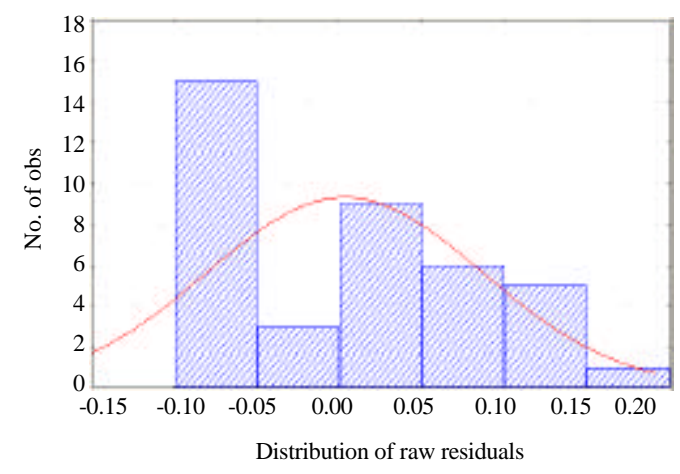

Fig. 30: The histogram and the natural distribution of the remaining values based on LSF

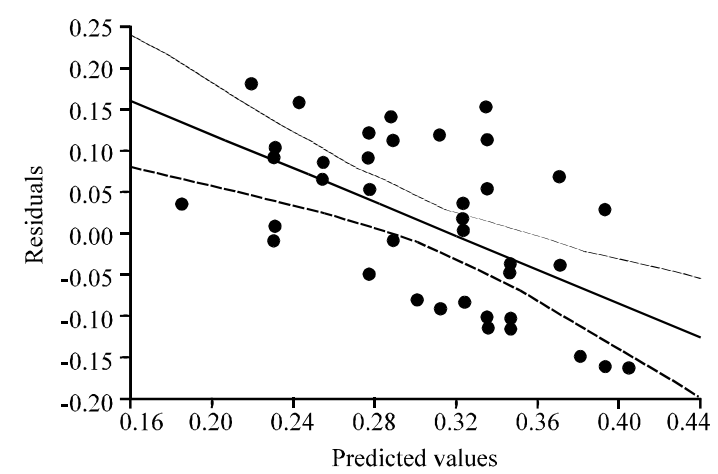

Fig. 31:The relationship between the residual and the estimated readings of the autoclave based on IST-MIN; Predicted vs. residual scores dependent variables: AUTO_EXP

readings of the autoclave based on $\mathrm{MgO}, \mathrm{CaO}$, Blane and the relationship between the actual readings and the estimated readings of the autoclave based on 


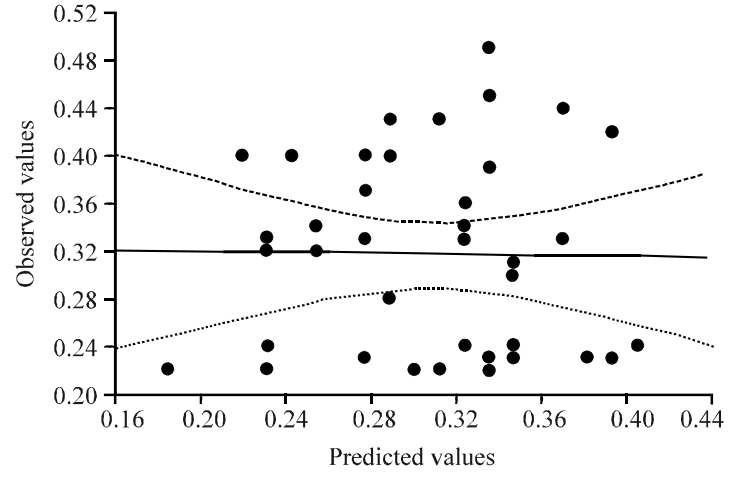

Fig. 32: The relationship between the actual readings and the estimated readings of the autoclave based on the IST-MIN; Predicted vs. observed values dependent variables: AUTO_EXP

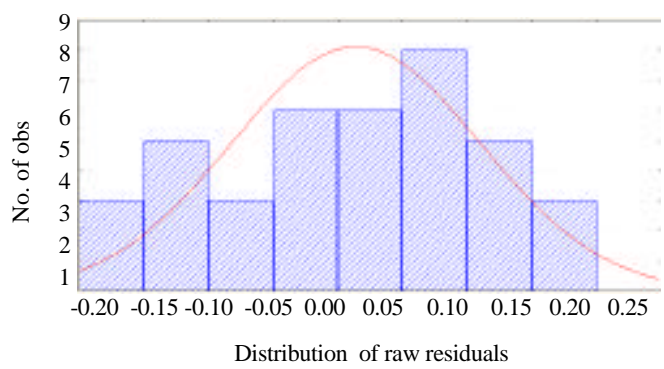

Fig. 33: Histogram and normal distribution of residual values based on SIT-MIN

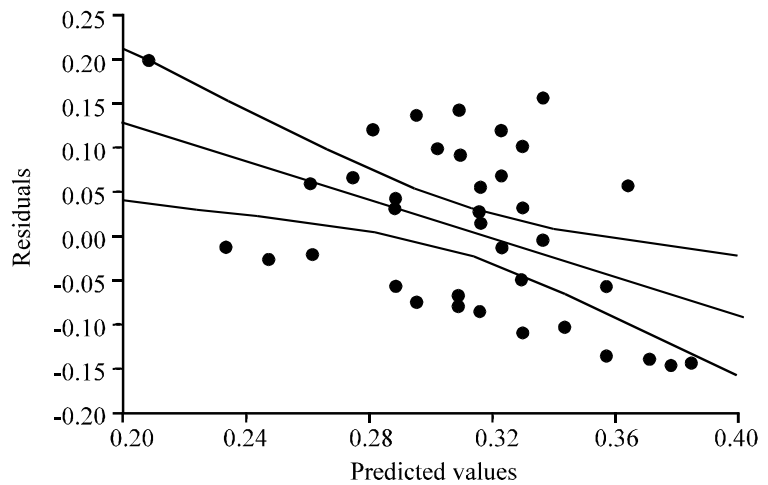

Fig. 34: The relationship between the residual and the estimated readings of the autoclave based on FST-MIN; Predicted vs. observed values dependent variables: AUTO_EXP

$\mathrm{MgO}, \mathrm{CaO}$, Blane are presented in Fig. 43 and 44. The distribution of residuals is shown in Fig. 45.

MgO, $\mathbf{C a O}, \mathrm{SO}_{3}: \mathrm{MgO}, \mathrm{CaO}, \mathrm{SO}_{3} \%$ was used as the independent variable in developing this model. The final

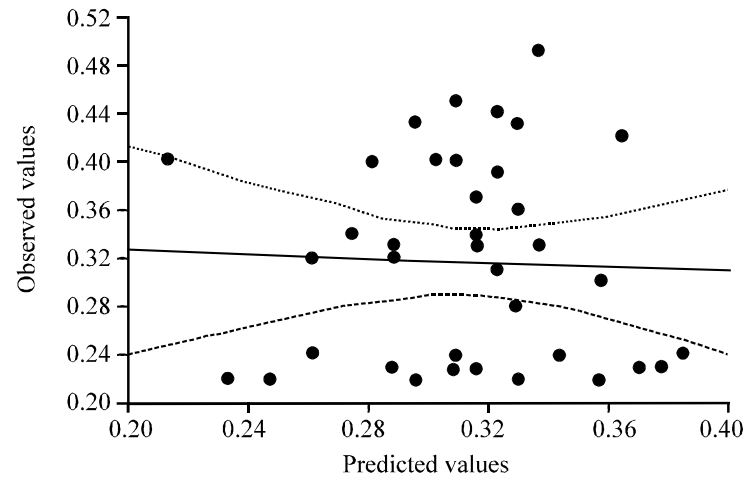

Fig. 35: The relationship between the actual readings and the estimated readings of the autoclave based on FST-MIN; Predicted vs. observed values dependent variables: AUTO_EXP

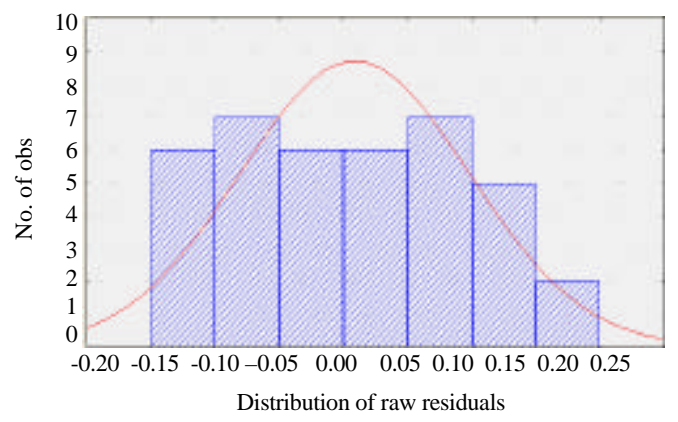

Fig. 36: The histogram and the natural distribution of the residual values of the autoclave based on FST-MIN

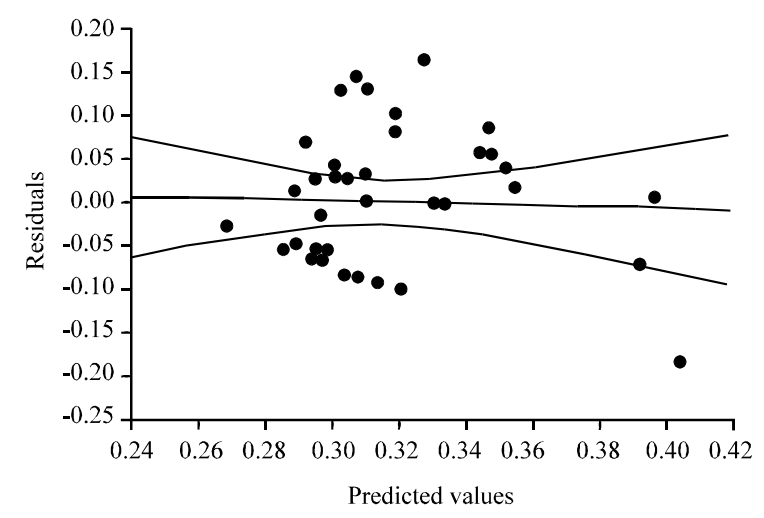

Fig. 37:Relationship between the residual and the estimated readings of the autoclave based on BLINE; Predicted vs. residual scores dependent variables: AUTO EXP

form of this model is as illustrated in Table 16. The relationship between the residuals and the estimated readings of the autoclave based on $\mathrm{MgO}, \mathrm{CaO}, \mathrm{SO}_{3}$ and 


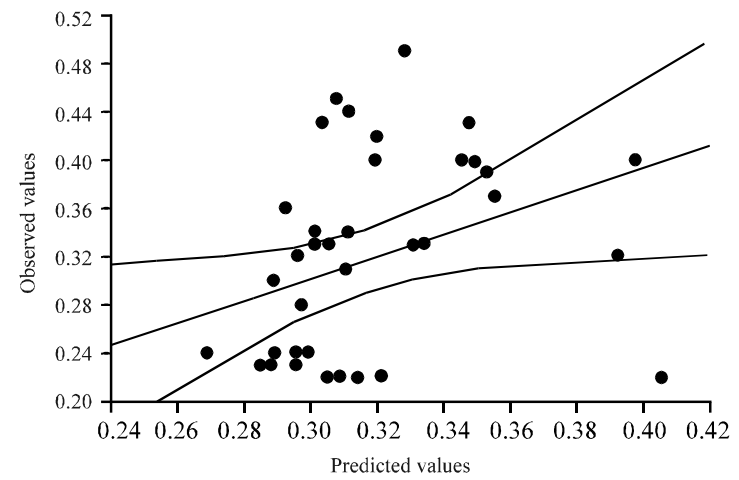

Fig. 38: The relationship between the actual values and the estimated values of the autoclave based on Bline rredicted vs. Predicted vs. observed values dependent variables: AUTO_EXP

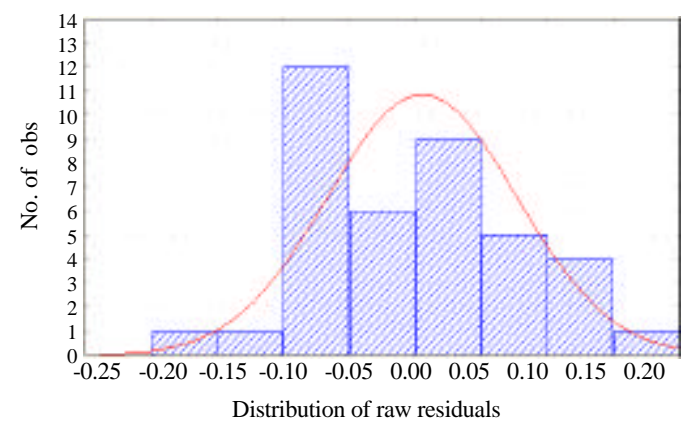

Fig. 39:Histogram and normal distribution of residual values based on Bline

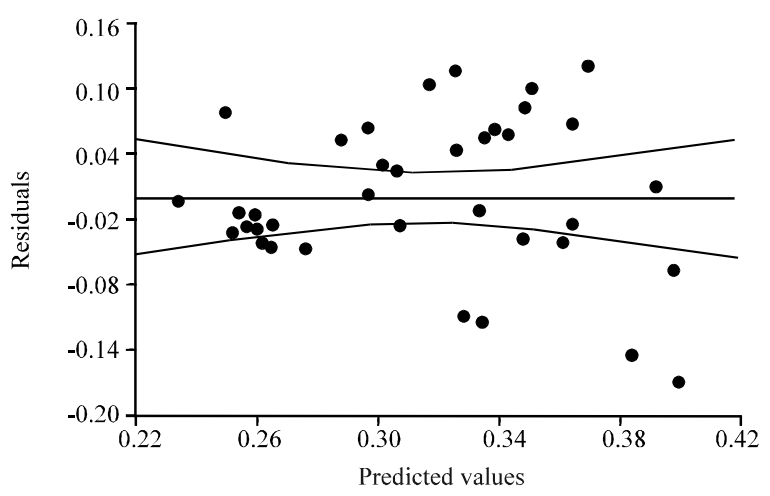

Fig. 40: The relationship between the residual and the estimated readings of the autoclave based on $\mathrm{MgO}, \mathrm{CaO}$; Predicted vs. residual scores dependent variables: AUTO_EXP

the relationship between the actual readings and the estimated readings of the autoclave based on $\mathrm{MgO}, \mathrm{CaO}, \mathrm{SO}_{3}$ are presented in Fig. 46 and 47. The distribution of residuals is shown in Fig. 48.

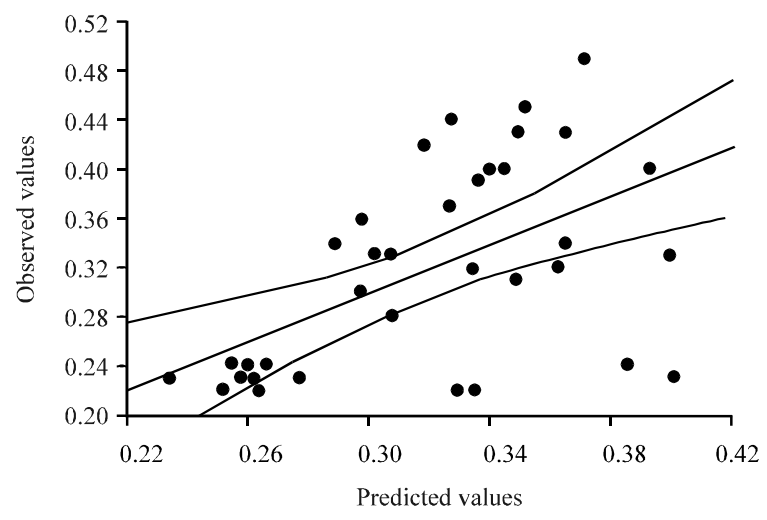

Fig. 41: The relationship between the actual readings and the estimated readings of the autoclave based on $\mathrm{MgO}, \mathrm{CaO}$; Predicted vs. observed values dependent variables: AUTO_EXP

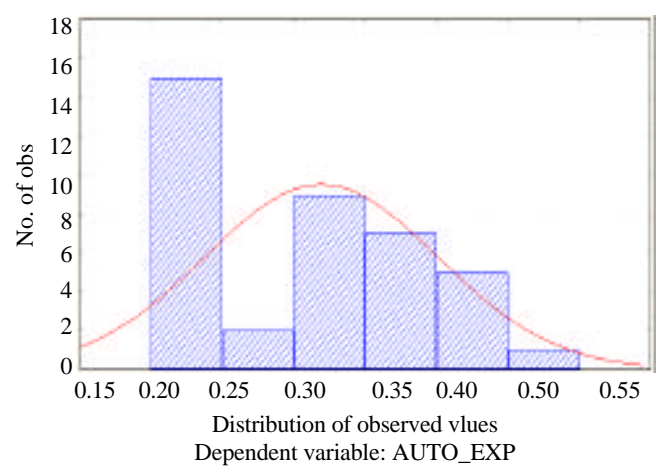

Fig. 42: The histogram and the natural distribution of the residual values of the autoclave based on $\mathrm{MgO}$, $\mathrm{CaO}$

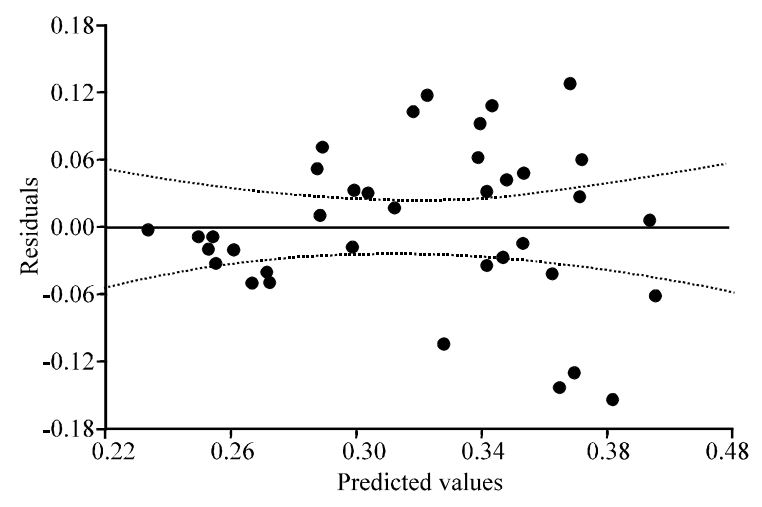

Fig. 43:Relationship between the residual and the estimated readings of the autoclave based on $\mathrm{MgO}, \mathrm{CaO}$, Blane; Predicted vs. residual scores dependent variables: AUTO_EXP

$\mathrm{MgO}, \mathrm{CaO}, \mathrm{SO}_{3}$, Blane: $\mathrm{MgO}, \mathrm{CaO}, \mathrm{SO}_{3}$, Blane was used as the independent variable in developing this 


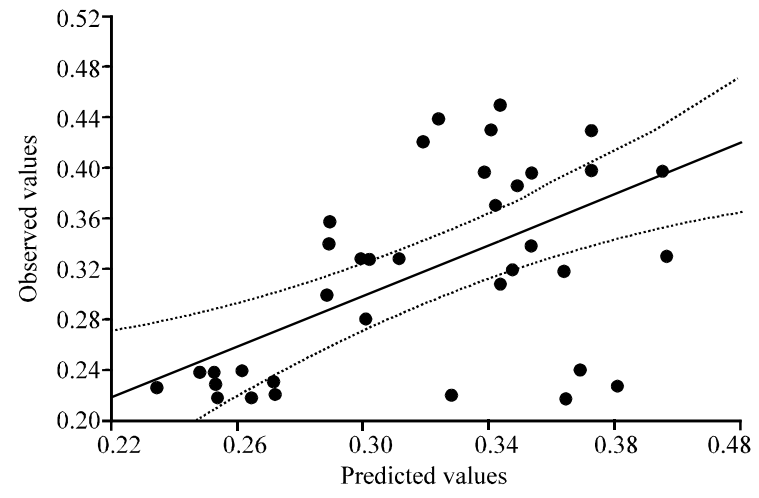

Fig. 44: The relationship between the actual readings and the estimated readings of the autoclave based on $\mathrm{MgO}, \mathrm{CaO}$, Blane; Predicted vs. observed values dependent variables: AUTO_EXP

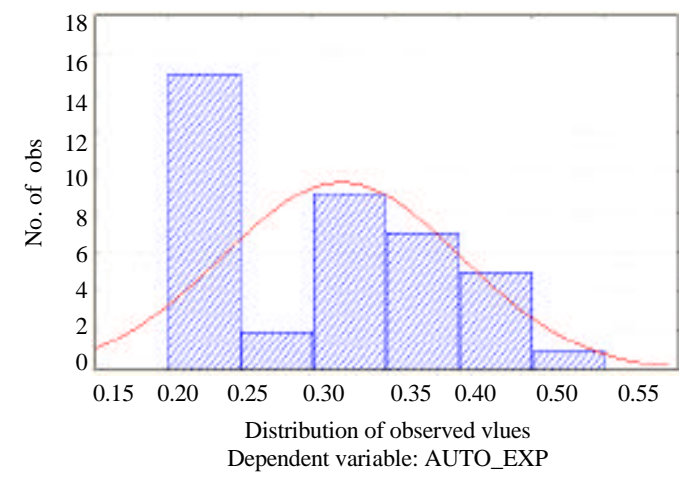

Fig. 45:Histogram and normal distribution of the remaining values of the autoclave based on $\mathrm{MgO}$, $\mathrm{CaO}$, Blane

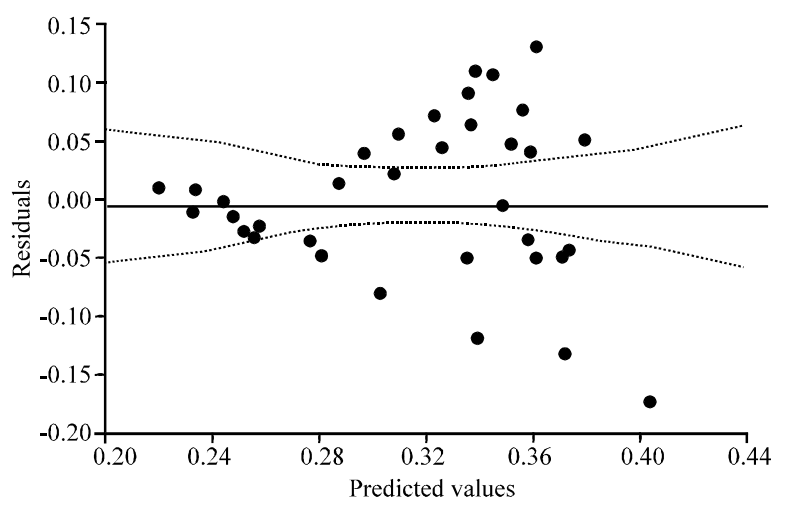

Fig. 46:Relationship between the residual and the estimated readings of the autoclave based on $\mathrm{MgO}, \mathrm{CaO}, \mathrm{SO}_{3}$; Predicted vs. residual scores dependent variables: AUTO_EXP

model. The final form of this model is as illustrated in Table 17. The relationship between the residuals and the

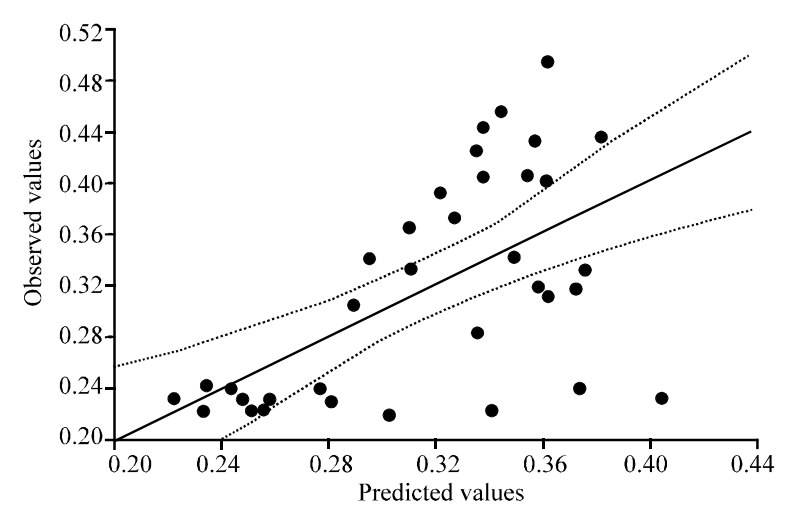

Fig. 47: The relationship between the actual readings and the estimated readings of the autoclave based on $\mathrm{MgO}, \mathrm{CaO}, \mathrm{SO} 3$; Predicted vs. observed values dependent variables: AUTO_EXP

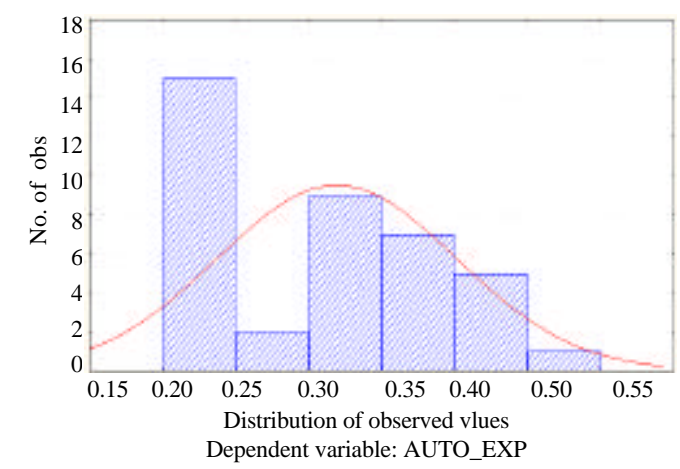

Fig. 48: The histogram and the natural distribution of the remaining values of the autoclave based on $\mathrm{MgO}$, $\mathrm{CaO}, \mathrm{SO}_{3}$

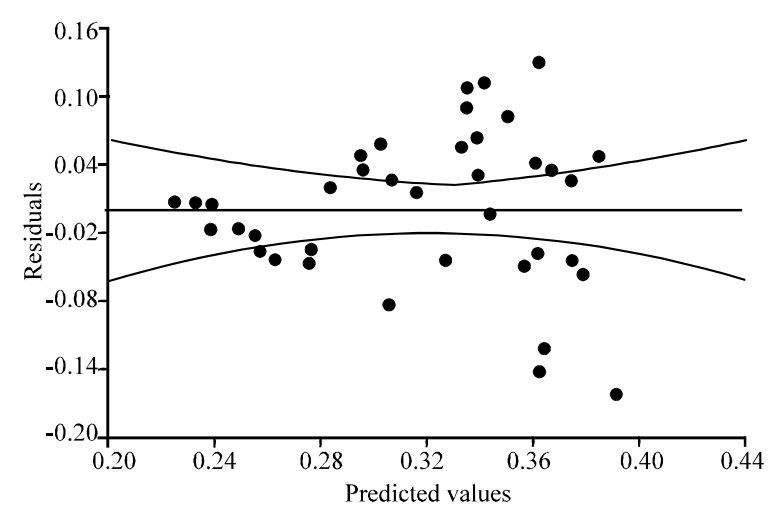

Fig. 49:The relationship between the residual and the estimated readings of the autoclave based on $\mathrm{MgO}, \mathrm{SO}_{3}, \mathrm{CaO}$, Blane; Predicted vs. residual scores dependent variables: AUTO_EXP

estimated readings of the autoclave based on $\mathrm{MgO}, \mathrm{CaO}$, $\mathrm{SO}_{3}$, Blane and the relationship between the actual 


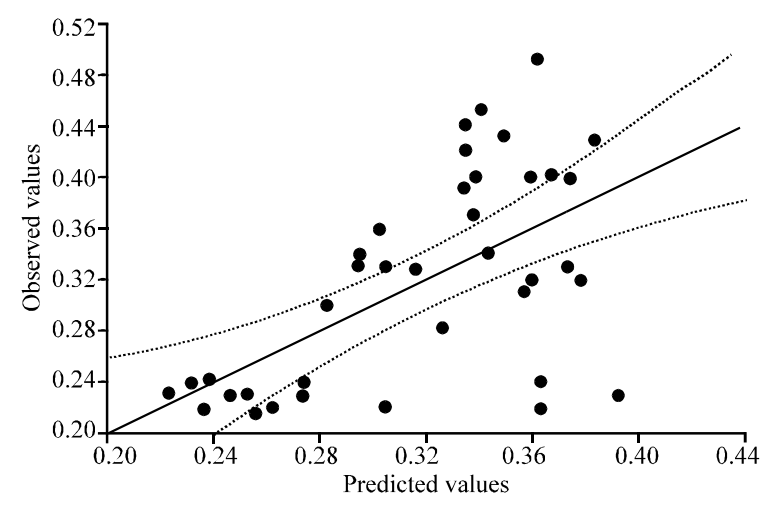

Fig. 50: Relationship between the actual readings and the estimated readings of the autoclave based on $\mathrm{MgO}, \mathrm{CaO}, \mathrm{SO}_{3}$, Blane; Predicted vs. observed values dependent variables: AUTO_EXP

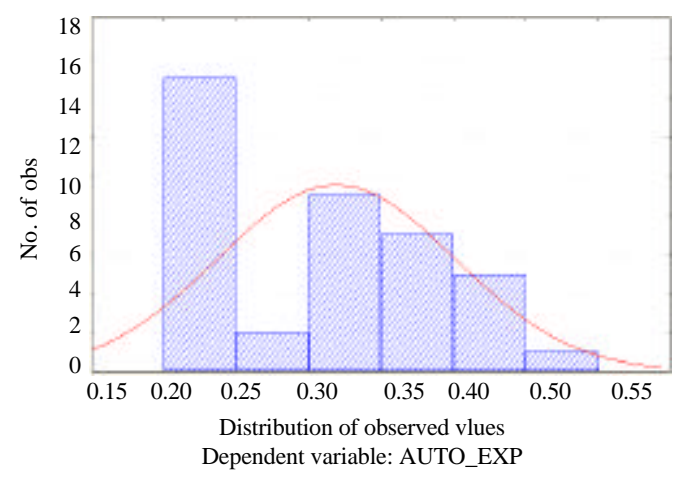

Fig. 51: The histogram and the natural distribution of the remaining values of the autoclave based on $\mathrm{MgO}$, $\mathrm{CaO}, \mathrm{SO}_{3}$, Blanel

readings and the estimated readings of the autoclave based on $\mathrm{MgO}, \mathrm{CaO}, \mathrm{SO}_{3}$, Blane are presented in Fig. 49 and 50 . The distribution of residuals is shown in Fig. 51.

The results of the correlation coefficient $(R)$ and $\left(R^{2}\right)$ for individual factors are very close and it was ranged between (0.916-0.976) and (0.84-0.953) for $(\mathrm{R})$ and $\left(\mathrm{R}^{2}\right)$, respectively, the results of the correlation coefficient $(\mathrm{R})$ for (free lime, L.S.F, $\mathrm{SiO}_{2}, \mathrm{CaO}, \mathrm{MgO}$ ) compounds was about (0.967). The results of both the IR, L.o.1 and $\mathrm{Fe}_{2} \mathrm{O}_{3}$ were close with the value of correlation coefficient $(\mathrm{R})$ with about (0.916). The results of F-values (F) for individual factors are came in varying values in range of (199-773), te results of both the IR, $\mathrm{LO} 1$ and $\mathrm{Fe}_{2} \mathrm{O}_{3}$ were close with the F-values (F) and the Standard Error (SE) with about (199) and (0.117), respectively. The results of (Blane) and aluminum oxide $\left(\mathrm{Al}_{2} \mathrm{O}_{3}\right)$ and sulfur compounds $\left(\mathrm{SO}_{3}\right)$ were convergent in the correlation coefficient $(\mathrm{R})$ of these compounds (0.971).
When studied the affecting factors on the results of the autoclave in groups, the correlation coefficient of $(\mathrm{MgO}, \mathrm{CaO})$ group was 0.785 and $(\mathrm{MgO}, \mathrm{CaO}$ and Blane $)$ group was $0.979\left(\mathrm{MgO}, \mathrm{CaO}, \mathrm{SO}_{3}\right)$ was 0.979 and $(\mathrm{MgO}$, $\mathrm{CaO}, \mathrm{SO}_{3}$ and Blane) was 0.98 . It is clear that the fineness of cement is the one of most interesting feature influencing the soundness of cement and the value of the correlation coefficient $(\mathrm{R})$ was improved when the fineness appear in models.

Fineness of cement is the most interesting factor affecting the soundness of cement. From this model it is clear that the autoclave expansion decreases with the increase in cement fineness. For the results of the individual factors the distribution of residuals are distributed normally and the residuals concentrated around the center (zero). This gives an indication that the models are adequate and no error in analysis and this the more suitable and recommended while the factors in groups shows a clear intercept to the side.

\section{CONCLUSION}

According to the results obtained in this study from the autoclave test, the following can be concluded: the multiple linear regression was found to be very suitable for predicting the autoclave expansion of Portland cement. Noted that, there is no significant difference in the value of correlation coefficient when studying the factors individually or in the form of groups, so, it is preferable to use equations with individual factors for ease of research.

\section{ACKNOWLEDGMENTS}

I would like to thank Kufa University for supporting my work and helped me get results of better quality. I am also, grateful to the research members and colleagues for their patience and support in overcoming numerous obstacles we have been facing through my research.

\section{REFERENCES}

Al-Attar, T.S., 2013. A mathematical model for predicting autoclave expansion for Portland cement. Intl. J. Civil Eng. Technol., 4: 110-116.

Anonymous, 2005. Standard test method for autoclave expansion of hydraulic cement. ASTM C151-05, ASTM International, West Conshohocken, Pennsylvania.

Borhan, T.M. and R.S. Al-Rawi, 2016. Soundness of cement paste due to combined effect of $\mathrm{MGO}$ and SOM3 contents in cement. Al Qadisiya J. Eng. Sci., 9: 492-502.

Chatterji, S., 1995. Mechanism of expansion of concrete due to the presence of dead-burnt $\mathrm{CaO}$ and $\mathrm{MgO}$. Cem. Concr. Res., 25: 51-56. 
Czermin, W., 1980. Cement Chemistry and Physics for Civil Engineers. Bauveflag, Wiesbaden, pp: 112-157.

Gonnerman, H.F., W. Lerch and T.M. Whiteside, 1953. Investigations of the hydration expansion characteristics of Portland cement. Portland Cement Association, Skokie, Illinois, USA. https://trid.trb.org/view/101988

Huntzinger, D.N. and T.D. Eatmon, 2009. A life-cycle assessment of Portland cement manufacturing: Comparing the traditional process with alternative technologies. J. Cleaner Prod., 17: 668-675.
Latif, M.A., 2001. Mathematical model for optimum gypsum content in concrete. Ph.D Thesis, University of Baghdad, Baghdad, Iraq.

Lea, F.M., 1970. The Chemistry of Cement and Concrete. 3rd Edn., Edward Arnold Publishers Limited, Glasgow, United Kingdom.

Lea, F.M., 2004. The Chemistry of Cement and Concrete. Elsevier, New York, USA., Pages: 1057.

Neville, A.M., 1995. Properties of Concrete. 14th Edn., Longman Group Limited, London, pp: 324.

Rehsi, S.S. and A.J. Majumdar, 1967. The use of small specimens for measuring autoclave expansion of cements. Mag. Concr. Res., 19: 243-246. 